\title{
SEMANA DO MEIO AMBIENTE: DESENVOLVIMENTO DE ATIVIDADES LÚDICAS NA EDUCAÇÃO INFANTIL E NOS ANOS INICIAIS DO ENSINO FUNDAMENTAL
}

\author{
Nathália Hernandes Turke ${ }^{1}$ \\ Hemilyn da Silva Meneguete ${ }^{2}$ \\ Elizabete Hernandes Marconi Soares ${ }^{3}$ \\ Angélica Florenzano Penha ${ }^{4}$ \\ Virgínia lara de Andrade Maistro ${ }^{5}$
}

Resumo: Este trabalho traz resultados acerca de aulas desenvolvidas durante os meses de maio e junho de 2019, expostas e apresentadas na semana do meio ambiente, com 143 estudantes da Educação Infantil e anos iniciais do Ensino Fundamental, em uma escola municipal, na cidade de Bom Sucesso, estado do Paraná, tendo como objetivo apontar a importância de trabalhar Educação Ambiental de maneira lúdica. Para tanto, foram desenvolvidas aulas com a utilização de música, paródia, poesia, filme, vídeos, bem como confecção de cartazes. É possível afirmar que, a partir das discussões ocorridas durante o processo, as crianças foram sensibilizadas quanto ao tema e passaram a questionar suas atitudes e de pessoas próximas perante o meio ambiente.

Palavras-chave: Educação Ambiental; Conservação; Ludicidade; Sensibilização Ambiental.

\footnotetext{
1 Universidade Estadual de Londrina. E-mail: nathalia.turke@hotmail.com

2 Faculdade Catuaí. E-mail: hemilyn_silva@hotmail.com

${ }^{3}$ Rede municipal de Bom Sucesso. E-mail: prof-elizabete40@hotmail.com

${ }^{4}$ Universidade Estadual de Londrina. E-mail: angelicaflorenzanopenha86@gmail.com

${ }^{5}$ Universidade Estadual de Londrina. E-mail: virginiamaistro@yahoo.com.br
} 
Abstract: This work brings results about lessons developed during the months of May and June of 2019, exposed and presented in the Environment Week, with 143 students of kindergarten and early elementary school, in a municipal school in the city of Bom Sucesso, state of Paraná, aiming to indicate out the importance of working Environmental Education in a playful way. To this end, classes were developed with the use of music, parody, poetry, film, videos, and making posters. It is possible to affirm that, from the discussions that took place during the process, the children were sensitized about the theme and began to question their attitudes and those of close people in relation to the environment.

Keywords: Environmental education; Conservation; Playfulness; Environmental Awareness.

\section{Introdução}

A constante degradação do meio ambiente nos leva a refletir a respeito da situação que nosso planeta se encontrará nas próximas décadas, gerando questionamentos a respeito das atitudes do ser humano perante ele. De acordo com Tilman et al. (2017), nos próximos 50 anos nossa biodiversidade estará à beira de um colapso; florestas podem virar desertos, recifes se tornarem sem vida, mesmo não havendo eventos cataclísmicos.

Enquanto a humanidade utiliza os recursos naturais excessivamente, transformando e impactando o ecossistema, surge a necessidade de sensibilizar a população a respeito da importância da conservação do meio ambiente, a fim de garantir a sobrevivência da fauna e da flora, bem como a qualidade de vida das gerações futuras.

É importante esclarecer que neste trabalho foi utilizado o termo conservação e não preservação por assumir conceitos referentes à "Biologia da Conservação", a qual surgiu a partir do "crescimento do arcabouço teórico acerca dos padrões de distribuição e das ameaças à biodiversidade" (FRANCO; SCHITTINI; BRAZ, 2015, p. 254). Ao contrário do preservacionismo, o qual parte do compromisso de salvar a natureza, sua fauna e flora, seus biomas, suas florestas, e assim por diante, independentemente do valor econômico e/ou social que poderia existir em determinadas áreas, a "Biologia da Conservação" está fundamentada em "uma ética de tutela responsável da natureza" (FRANCO; SCHITTINI; BRAZ, 2015, p. 255), ou seja, parte da necessidade de o ser humano compreender e proteger a natureza, fazendo uso da mesma de maneira racional, levando a "atitudes que valorizam os seres humanos como uma, ainda que única, dentre as milhões de outras espécies do planeta" (FRANCO; SCHITTINI; BRAZ, 2015, p. 265).

Partindo-se da necessidade de formar cidadãos críticos perante o meio ambiente e a sociedade, a Educação Ambiental (EA) é de suma importância nos dias atuais, configurando-se como um elemento básico para 0 desenvolvimento social, por desencadear um processo reflexivo na vida dos indivíduos (CECHIN, 2010), tendo a escola grande responsabilidade na sensibilização das crianças e jovens acerca das questões ambientais. 
Segundo Adams (2005), a EA deve assumir um caráter mais realista, buscando um equilíbrio entre o homem e o ambiente. Por conseguinte, Reigota (1998, p. 43) evidencia que a EA deve levar a propostas pedagógicas centradas na conscientização, mudança de comportamento, desenvolvimento de competências, capacidade de avaliação e participação ativa dos educandos. Portanto, Pelicioni (1998) afirma que o objetivo da EA é formar a consciência dos cidadãos, transformando-se em filosofia de vida, de logo a levar a adoção de comportamentos ambientalmente adequados. A Educação Ambiental deve, necessariamente, transformar-se em ação. Entretanto,

a Educação Ambiental ainda não é de fato aplicada pelas famílias e, assim, a responsabilidade da educação nas escolas se amplia. Muitas vezes são os mais novos que levam para casa hábitos mais saudáveis estudados nas salas de aula (FERREIRA; SANTOS; SANTOS, 2018, p. 123).

Sem sensibilização com relação às mudanças de hábitos perante as agressões ao meio ambiente, não haverá "construção de valores e de postura que sejam éticos [...], onde o ser humano se enxergue como principal agente de transformação ambiental e de degradação do mesmo" (SOUZA, 2014, p. 250).

Nada mudará sem que ocorra mudanças na forma de pensamento. É a forma com que pensamos que nos faz atuar e modificar hábitos e costumes, modifcando nossas ações. Se não houver sensibilização, não haverá novas formas de pensar e tampouco de agir (FERREIRA; SANTOS; SANTOS, 2018, p. 123).

Sendo assim, trabalhar Educação Ambiental em sala de aula auxilia no processo da aprendizagem, nos aspectos cognitivos, afetivos e sociais, proporciona espaços de prazer que desafiam às descobertas, desenvolve o pensamento crítico perante à sociedade e à conservação da natureza, visto que "crianças bem informadas sobre os problemas ambientais vão ser adultos mais preocupados com o meio ambiente" (MEDEIROS, 2001, p. 2).

Desta forma, este trabalho tem como objetivo apontar a importância de trabalhar Educação Ambiental na Educação Infantil e nos Anos Iniciais do Ensino Fundamental de maneira lúdica. Para tanto, trazemos resultados obtidos durante aulas lúdicas desenvolvidas durante um mês. 


\section{O lúdico em aulas de Educação Ambiental}

O lúdico está relacionado ao brincar, brincadeiras e jogos e, por isso, tem papel importante no desenvolvimento da criança, sendo capaz de formular ligações entre o ser humano e o mundo desde o início da vida. A ludicidade na vida da criança é primordial para o seu desenvolvimento integral, como elucida Hendler (2010) ao dizer que as atividades vivenciadas pelo lúdico proporcionam a aprendizagem e desenvolvimento do indivíduo em seu processo amplo.

Aprender brincando é uma maneira de se construir conceitos, habilidades e conhecimentos, visto que estas experiências serão lembradas durante a vida. Santos (1997) afirma que o

brincar ajuda a criança no seu desenvolvimento físico, afetivo, intelectual e social, pois, através das atividades lúdicas, a criança forma conceitos, relaciona ideias, estabelece relações lógicas, desenvolve a expressão oral e corporal, reforça habilidades sociais, reduz a agressividade, integra na sociedade e constrói seu próprio conhecimento (SANTOS, 1997, p. 20).

A escola como instituição de ensino deve utilizar-se do lúdico como recurso didático, a fim de favorecer a aprendizagem. "Através do lúdico a escola estimula a criança a uma melhor relação com o seu ambiente social" (HENDLER, 2010, p. 23), ou seja, as atividades lúdicas desenvolvidas neste espaço podem proporcionar habilidades cognitivas, motoras, fortalecer vínculos sociais, preparando os jovens para a convivência em sociedade. Diante disto, ao levarmos a Educação Ambiental para a sala de aula, trabalhá-la de maneira lúdica é uma excelente alternativa.

Levando-se em consideração que todo indivíduo é parte integrante da sociedade e do meio ambiente, a conservação deste é indispensável para haver sustentabilidade e, ao atrelar Educação Ambiental ao lúdico, o estudante passa a ser capaz de internalizar seu papel na sociedade, se colocando como agente transformador, se posicionando criticamente e percebendo que pequenas ações fazem a diferença (CECHIN, 2010). Assim,

a Educação Ambiental nas escolas pode ser promovida através da ludicidade, como método de estímulo à conscientização dos temas ecológicos diversos, pois a metodologia lúdica possibilita uma variedade de práticas de interação e motivação mútua e consequentemente de uma aquisição mais eficaz do conhecimento (RANGEL; MIRANDA, 2016, s.p,) 
Contudo, ao se utilizar do lúdico como recurso didático para trabalhar Educação Ambiental, o professor deve planejar suas aulas de acordo com a faixa etária de cada aluno, conhecer suas particularidades, ritmos de aprendizagem e de dificuldade e assim por diante. Desta forma, o docente torna-se capaz de selecionar os melhores recursos e estímulos, adotando uma metodologia capaz de auxiliar na compreensão dos participantes, não se esquecendo de que estes devem se sentir confortáveis, a fim de, ao interagirem ludicamente, aprenderem de maneira prazerosa.

Segundo Cechin (2010, p. 20), o professor deve trabalhar Educação Ambiental "através de atividades lúdicas, criando uma experiência pedagógica prazerosa e rica de sentido social, permitindo trabalhar os mais variados conteúdos sem deixar de proporcionar alegria e conhecimento aos educandos". Desta forma seria possível alcançar e envolver as crianças de modo com que aprendam os conteúdos de maneira prazerosa.

Alguns recursos lúdicos metodológicos podem ser explorados ao abordar temas ambientais na Educação Infantil e nos Anos Iniciais do Ensino Fundamental, como confecção de cartazes, músicas, paródias, poemas, trava-línguas, charges e quadrinhos, vídeos, filmes, teatros, jogos, gincanas, atividades fora da sala de aula, entre outros. Neste trabalho foram explorados alguns destes recursos, os quais serão apresentados a seguir.

\section{Procedimentos metodológicos}

Este projeto foi desenvolvido em uma escola municipal, na cidade de Bom Sucesso, no estado do Paraná, entre os dias 06 de maio e 05 de junho de 2019. Foram trabalhadas aulas expositivas e lúdicas, em uma turma da Educação Infantil (Pré) e seis turmas dos anos iniciais do Ensino Fundamental (dois primeiros anos, dois segundos anos, um quarto ano e um quinto ano), totalizando 143 alunos, com os seguintes temas: aquecimento global, efeito estufa, ciclo da água, lixo, coleta seletiva, lixão e aterro sanitário, conservação do meio ambiente, desmatamento, queimadas, agrotóxicos e tráfico de animais. Para o desenvolvimento das aulas foram utilizados os seguintes recursos didáticos:

a) Vídeos: foram utilizados vídeos, a fim de ilustrar os temas: aquecimento global, ciclo da água, lixão e aterro sanitário. Para tanto, foram utilizados os vídeos intitulados: "Aquecimento Global" (CODAU, 2010); "Aterro Sanitário x Lixão" (ECOPESA AMBIENTAL, 2012); "O Ciclo da Água" (CODAU, 2008).

b) Música e Paródia: foi selecionada a música "Bia - O lixo no lixo" (BIANCARDI, 2015) e a paródia "50 reais - Naiara Azevedo - Paródia Meio Ambiente" (BELINGER, 2017), as quais abordam a importância de jogar o lixo no local correto, não praticar queimadas e desmatamentos, $e$ as consequências destes atos para o meio ambiente. A música foi trabalhada na íntegra, sendo a letra: 
Vamos limpar esse mundo jogando lixo no lixo. Não jogue nada nas ruas, se não você passa por bicho. Fumaça sempre suja o ar. Por isso não faça fogueira. A natureza está cansada, não aguenta com tanta sujeira. Tem peixes morrendo nos rios. $\mathrm{O}$ ar não da para respirar. Onde está a educação? Até quando vamos suportar? (BIANCARDI, 2015, on-line).

Já a paródia sofreu algumas modificações, visto que foi criada especificamente para uma gincana, sendo necessárias algumas adaptações para ser trabalhada em sala de aula. A letra trabalhada foi a seguinte:

Que bonito, hein! Que bonito, hein! Que cena mais linda, será que eu estou atrapalhando o lenhador aí? Que lixo! Cê tá de brincadeira! Vocês não percebem, tão desmatando a Terra inteira! O mundo não é de papel. A fumaça das indústrias poluindo o céu. Nossos rios eram doces, lindos como mel e agora virou um lixão. Parem já de poluir o mar, salvem todos os peixinhos que vivem por lá Que decepção! Lá não é lugar de jogar lixo não! [Eu vou economizar água junto com você, apagando sempre as luzes ninguém vai perder porque] aquele que protege a nossa natureza vai ser um campeão com certeza (BELINGER, 2017, on-line).

c) Poesia: a poesia "Cuidando da Natureza", de Leila Maria Grillo (2010), foi utilizada como norteadora para discussões sobre desperdício da água, reciclagem, poluição, aquecimento global e conservação do meio ambiente. A poesia pode ser visualizada a seguir:

Vamos cuidar/ Da mãe Natureza/ Preservando a vida/ Do nosso Planeta./ Não desperdicem água/ Para não faltar/ Separe todo lixo/ Para reciclar./ Não destruam as matas/ Árvores e flores/ Que enfeitam o mundo/ Com as suas cores./ Não poluam o ar/ Isso não é legal/ $\mathrm{Na}$ certa vai causar/ O aquecimento global./ Vamos trabalhar/ Nessa tarefa urgente/ Para preservar/ O nosso meio ambiente (GRILLO, 2010, online).

d) Filme: com o intuito de trabalhar tráfico de animais, os alunos assistiram ao filme "Tainá: uma aventura na Amazônia" (LAMARCA; BLOCH, 2001), o qual retrata a estória de uma índia, a qual vive com seu avô na floresta amazônica. Tainá se torna guardiã da floresta, sendo responsável por impedir o contrabando de animais. Com este filme foi possível discutir sobre tráfico de animais silvestres e extinção.

Além disto, os alunos confeccionaram cartazes, os quais foram expostos nas paredes da escola na Semana do Meio Ambiente. Esta semana começa no dia 01 de junho e vai até o dia 05 de junho, data em que se é 
comemorado o "Dia Mundial do Meio Ambiente" (BRASIL, 1981). Ainda, no dia 05 de junho, os alunos do quarto e quinto anos apresentaram a música e a paródia trabalhadas durante as aulas para toda a escola - para as apresentações, os alunos confeccionaram chocalhos utilizando "rolo" de papel higiênico, latas de refrigerante, arroz e feijão.

\section{Resultados e discussão}

Com relação à utilização de vídeos e filmes durante as aulas de Educação Ambiental, foi possível perceber que, a partir da visualização de conceitos e situações até então pouco conhecidas, os alunos se interessaram pelo que estavam aprendendo - mais do que quando o mesmo assunto foi exposto teoricamente antes da exposição do vídeo. Ademais, o uso de músicas, paródias e poemas também possibilitou interações, expressões corporais, e expressiva participação durante as discussões.

Após assistirem ao filme "Tainá: uma aventura na Amazônia", e o tema "Tráfico de Animais" ser discutido, muitos se mostraram indignados com as atitudes dos seres humanos perante aos animais, bem como "desesperados", por afirmarem conhecer pessoas que possuem animais exóticos em casa, em sua maioria pássaros. Uma das crianças, por exemplo, afirmou conhecer uma pessoa que tem um monte. Por conta disto, foi conversado e mostrado as implicações advindas da criação de animais silvestres em cativeiro e a dificuldade de reintrodução destes em seus habitats naturais, ou seja, as consequências do contrabando. Também foram relatadas "dicas" sobre o que é possível fazer se conhecer alguém que possui um animal proveniente do tráfico, com quem entrar em contato para efetuar a denúncia.

Após todos os temas terem sido trabalhados, os discentes confeccionaram cartazes, em que algumas ideias foram indicadas pela professora e outras por eles próprios. Alguns quiseram desenhar sobre a diferença de "como eles veem o mundo" e de "como eles queriam que o mundo fosse". Os cartazes confeccionados podem ser visualizados nas Figuras 1 e 2 e foram, posteriormente, expostos no pátio da escola. 


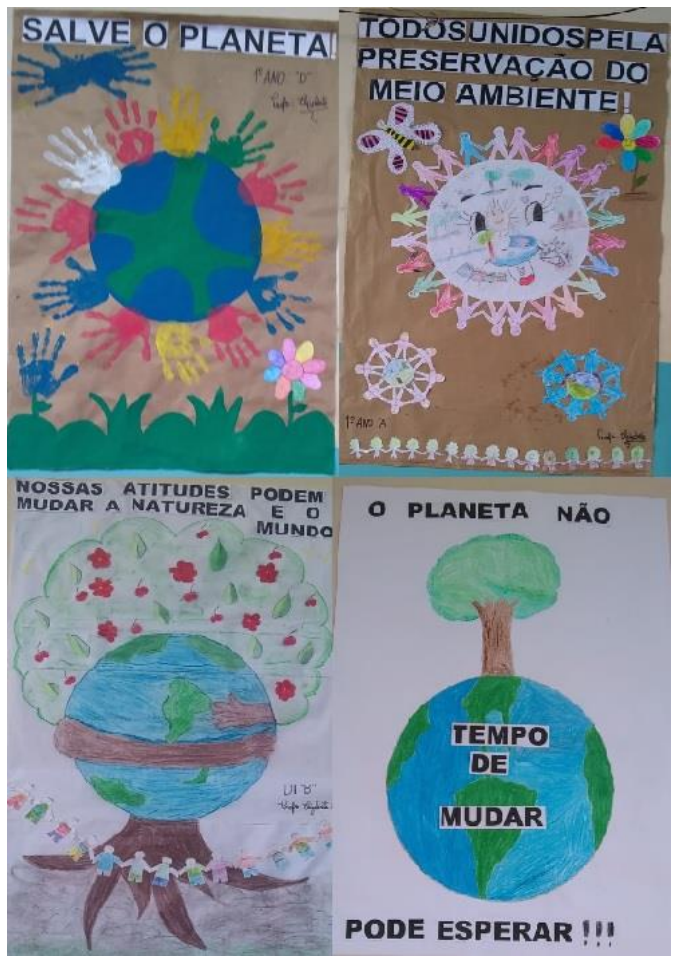

Figura 1: Cartazes confeccionados pelos alunos. Fonte: Os próprios autores.

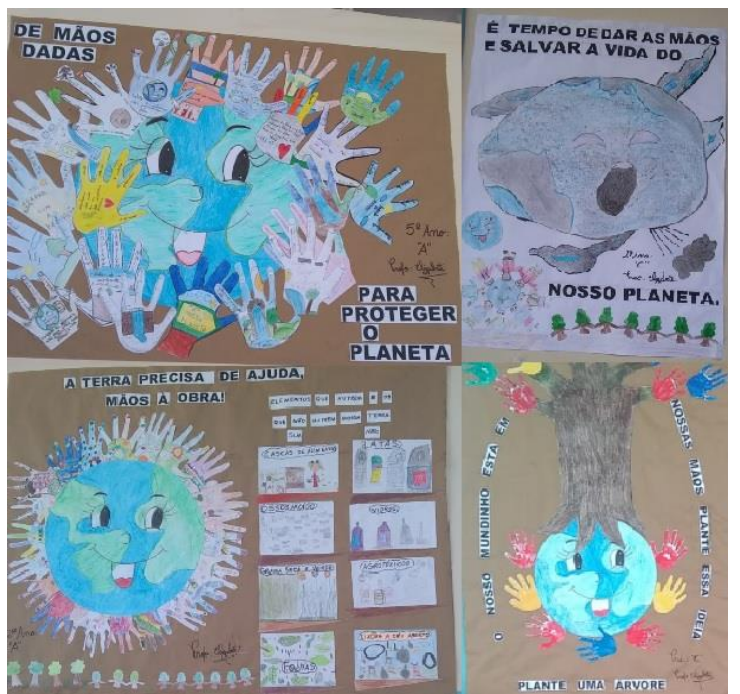

Figura 2: Cartazes confeccionados pelos alunos. Fonte: Os próprios autores.

Além do que foi possível perceber no decorrer das aulas, durante o mês em que estes temas foram trabalhados, algumas árvores na rua da escola foram cortadas, levando os alunos a questionar a diretora o motivo, elucidando a importância de não provocar desmatamentos. Além disso, passaram a jogar papéis, pedaços de lápis e borracha nas latas de lixo, além de "chamarem atenção" de quem jogava no chão, indicando a importância de dar destino adequado ao lixo. Desta forma, é possível inferir que aulas lúdicas com a utilização de vídeos, filmes, poemas, músicas, paródias se mostram importantes recursos didáticos ao se trabalhar um tema tão abrangente e importante como Educação Ambiental, sendo capaz de levar os jovens a questionarem atitudes errôneas, sensibilizando-os acerca da importância e necessidade de conservar o meio ambiente.

\section{Considerações finais}

Foi possível perceber a partir das indagações iniciais que os educandos possuíam uma ideia simplista do que é Educação Ambiental, limitada ao estudo e conservação do meio ambiente. Contudo, com o passar das aulas, perceberam que não era apenas isso. Além de compreenderem que Educação Ambiental engloba diversos contextos além do estudo e conservação, como tráfico de animais, coleta seletiva, lixo, água, agrotóxicos, efeito estufa, aquecimento global, e assim por diante, passaram a questionar a si mesmos e aos outros a respeito de determinadas atitudes. 
Não é possível dizer se haverá (ou não) mudanças nas atitudes destas crianças perante o meio ambiente, mas é possível afirmar que, a partir das discussões ocorridas nestas aulas, eles se sensibilizaram, começaram a pensar e questionar. Ainda, a utilização do lúdico se mostrou uma ferramenta importante ao se trabalhar assuntos ambientais na Educação Infantil e nos Anos Iniciais do Ensino Fundamental, visto que ao colocar esta modalidade didática e recursos disponíveis em prática, ao fazê-los pesquisar assuntos ligados ao meio ambiente, a fim de confeccionar cartazes, aprender letras de músicas e apresentar a real situação do meio ambiente a partir de vídeos e filmes, foi possível levá-los a conhecer e se interessar pelos temas ambientais.

Outrossim, a partir da utilização de aulas lúdicas, os participantes permaneceram livres para decidir sobre os temas que gostariam de expor, desenhar e apresentar para o restante da escola, se mostrando dispostos a aprender, discutir e refletir sobre os temas trabalhados. Além disto, alguns alunos se sentiram com liberdade para opinar sobre as aulas e pedir que, posteriormente, fossem levados para fora da escola, a fim de conhecer o meio ambiente de sua cidade. Pedidos estes, que foram atendidos no segundo semestre do ano letivo.

É necessário frisar que este trabalho é o primeiro passo de uma linha contínua e de um movimento inicial. Faz-se necessário trabalhar Educação Ambiental nas escolas, em todas as faixas etárias, com a utilização de diferentes recursos didáticos e de maneira transdisciplinar, a fim de levar as crianças e jovens a se sensibilizarem, refletirem, repensarem e, quem sabe, modificarem suas atitudes perante o meio ambiente.

\section{Agradecimentos}

À CAPES e à Fundação Araucária pelo apoio financeiro.

\section{Referências}

ADAMS, B. G. O que é Educação Ambiental: definições de Educação Ambiental. Projeto Apoema - Educação Ambiental, 2005. Disponível em: http://projetoapoema.blogspot.com.br/2011/01/mata-atlantica-conhecer-evivenciar.html. Acesso em: 05 nov. 2019.

BRASIL. Decreto no 86.028, de 27 de Maio de 1981. Institui em todo Território Nacional a "Semana Nacional do Meio Ambiente", e dá outras providências. Publicação original no Diário Oficial da União, Seção I, página 9810, 1981.

BELINGER, G. 50 Reais - Naiara Azevedo - paródia meio ambiente. 2017. Disponível em: <https://www.youtube.com/watch?v=kVBctmnPlwl>. Acesso em: 10 jul. 2019.

BIANCARDI, O. Bia - o lixo no lixo. 2015. Disponível em: <https://www.youtube.com/watch?v=Rab29EjZ8RM>. Acesso em: 10 jul. 2019. 
CECHIN, A. Trabalhando a Educação Ambiental através dos aspectos lúdicos em uma classe de séries iniciais do Ensino Fundamental no município de Santa Maria. Monografia (Especialização em Educação Ambiental) - Universidade Federal de Santa Maria - RS, Santa Maria, 2010.

CODAU. Aquecimento global. 2010. Disponível em: $<$ https://www.youtube.com/watch?v=93yZr azD0o $>$. Acesso em: 10 jul. 2019.

CODAU. 0 ciclo da água. 2008. Disponível em: $\leq$ ttps://www.youtube.com/watch?v=g26Wk4gpkws >. Acesso em: 10 jul. 2019.

ECOPESA AMBIENTAL. Aterro sanitário $x$ lixão. 2012. Disponível em: $<$ https://www.youtube.com/watch?v=xUJdWSrfM k>. Acesso em: 10 jul. 2019.

FERREIRA, A.; SANTOS, L.; SANTOS, R. A sensibilização ambiental como forma de incentivar crianças a se engajarem em um modelo de vida sustentável. Revista Extensão \& Sociedade, edição especial do 8o Congresso Brasileiro de Extensão Universitária, Natal, 2018.

FRANCO, J. L. A.; SCHITTINI, G. M.; BRAZ, V. S. História da conservação da natureza e das áreas protegidas: panorama geral. Historiæ, [s. I.], v. 6, n. 2, 2015.

GRILLO, L. M. Cuidado da natureza. 2010. Disponível em: <http://poesiaparacrianca.blogspot.com/2010/07/cuidando-da-natureza.html>.

Acesso em: 10 jul. 2019.

HENDLER, V. B. O lúdico nas primeiras séries do Ensino Fundamental. Trabalho de Conclusão de Curso (Licenciatura em Pedagogia) - Faculdade de Educação da Universidade Federal do Rio Grande do Sul, Porto Alegre, 2010.

LAMARCA, T.; BLOCH, S. Tainá: uma aventura na Amazônia. Rio de Janeiro: Art Films, 2001.

MEDEIROS, A.B.; MENDONÇA, M.J.S.L.; SOUSA, G.L.; OLIVEIRA, I.P. A importância da Educação Ambiental na escola nas séries iniciais. Revista Eletrônica Faculdade Montes Belos, v.4, n.1, 2011.

PELICIONI, M. C. F. Educação Ambiental, qualidade de vida e sustentabilidade. Saúde e sociedade, v. 7, n. 2, p. 19-31, 1998.

RANGEL, T. P.; MIRANDA, A. C. Atividade lúdica como inserção da Educação Ambiental no Ensino Fundamental. Educação Ambiental em Ação, [s. I.], n. 55, ano XIV, 2016.

REIGOTA, M. Desafios à Educação Ambiental escolar. In: CASCINO, F.; OLIVEIRA, J. F.; JACOBI, O. (Orgs.). Educação, meio ambiente e cidadania: reflexões e experiências. São Paulo: SMA, 1998.

SANTOS, S.M.P. O lúdico na formação do educador. Petrópolis: Vozes, 1997.

SOUZA, M. C. C. Educação Ambiental e as trilhas: contexto para a sensibilização ambiental. RevBea, v. 9, n. 2, São Paulo, 2014.

TILMAN, D.; MICHAEL, C.; WILLIAMS, D. R.; KIMMEL, K.; POLASKY, S.; PACKER, C. Future threats to biodiversity and pathways to their prevention. Nature, [s. I.], v. 546, 2017. 